\title{
O impacto de choques no setor cultural brasileiro: uma análise de emprego e renda à luz dos cortes orçamentários
}

The impact of shocks on the Brazilian cultural sector: an analysis of employment and income in the light of budget cuts

\author{
Marcus Vinícius Amaral e Silva (1) \\ Danyella Juliana Martins de Brito (2) \\ (1) Universidade Federal do Piaú \\ (2) Universidade Federal de Pernambuco
}

\section{Resumo}

As recentes mudanças nas políticas públicas voltadas à cultura brasileira, como a perda do status de ministério e as alterações na Lei de Incentivo à Cultura, vêm suscitando uma série de questionamentos quanto a importância do setor para a economia. Neste contexto, este artigo analisa como uma redução no consumo de bens e serviços do setor cultural impacta na produção, no rendimento e no emprego do próprio setor e das demais atividades econômicas. Para tal, emprega-se como metodologia o modelo de insumo-produto, para dados de 2015. Os resultados demonstram que os efeitos do choque proposto são percebidos em diversos setores da economia, em especial para aqueles fornecedores diretos de insumos para o setor cultural. Adicionalmente, há uma importante redução nos postos de trabalho e no rendimento das familias, não contida apenas no setor cultural, mas propagada para toda a economia.

\section{Palavras-chave}

setor cultural, insumo-produto, análise setorial.

Códigos JEL R15, Z10. 


\section{Introdução}

A reflexão da dimensão cultural como parte essencial do processo de desenvolvimento econômico brasileiro possui uma literatura teórica consolidada (Cunha; Britto, 2017; Furtado, 1999). Esse movimento teórico contribuiu para explicar a dinâmica do desenvolvimento, atribuindo ao processo de formação cultural um papel de destaque. Quando a cultura é vista como instrumento de modernização da sociedade ela tem o potencial de transcender os resultados meramente econômicos. Não obstante a existência dessa perspectiva teórica consolidada, alguns avanços precisam ser conduzidos para entender empiricamente por quais vias o setor cultural pode gerar desenvolvimento econômico.

Segundo os dados da Pesquisa Nacional por Amostra de Domicílios Contínua (PNAD Contínua), em 2018, do total de ocupados (formal e informal), 5,7\% dos indivíduos exerciam como atividade principal alguma função no setor cultural. Dentro de um contexto de crise econômica, a atividade tem apresentado significativas mudanças quanto à formalidade dos empregos no setor. A proporção dos trabalhadores com carteira assinada passou de 44\% em 2014 para 34,5\% em 2018 (IBGE, 2019).

Embora no dia 07 de novembro de 2019 tenha ocorrido a transferência da Secretaria Especial da Cultura para o Ministério do Turismo, foi a partir de 24 de abril de 2019 que foram anunciadas diversas mudanças referentes ao setor cultural. $O$ Ministério da Cultura passou a fazer parte, como Secretaria Especial da Cultura, do Ministério da Cidadania. ${ }^{1}$ Ocorreram diversas modificações na Lei de Incentivo à Cultura de $n^{\circ} 8.318$, de 23 de dezembro de 1991, criada por Sergio Paulo Rouanet. Essas alterações visam aumentar a acessibilidade ao setor, como também descentralizar a cultura do eixo Rio-São Paulo. Entre as principais mudanças estão a redução no valor máximo de captação por projeto de $\mathrm{R} \$ 60$ milhões para $\mathrm{R} \$ 1$ milhão; um teto de $\mathrm{R} \$ 50$ para $10 \%$ dos ingressos; e o estabelecimento de cota mínima de ingressos gratuitos de $20 \%$ a $40 \%$ do total de entradas para distribuição às famílias de baixa renda. A partir das referidas mudanças na lei de incentivo à cultura, em síntese, é possível que os ingressos fiquem

1 Além da Secretaria de Cultura, o Ministério da Cidadania englobava o Ministério do Esporte, o Ministério do Desenvolvimento Social, a Secretaria Nacional de Políticas sobre Drogas (SENAD), e o Bolsa Família. Atualmente, a Secretaria Especial da Cultura faz parte do Ministério do Turismo. 
mais caros, ${ }^{2}$ que haja menos eventos de grande porte (shows e peças musicais) e que o número de equipamentos culturais aumente. Fica evidente que as alterações na lei de incentivo à cultura trazem aspectos ambíguos para a sociedade. Diante desse cenário, é preciso considerar que reduzir o investimento em cultura pode dessecar a trajetória de crescimento de um setor que demora anos para se desenvolver. Os mecanismos de apoio à cultura, que se traduzem em incentivos governamentais, são importantes para a produção cultural.

Nesse contexto, destacam-se também importantes mudanças ocorridas no setor cultural que atuam no sentido de asfixiar a atividade. Entre o início de 2019 e fevereiro de 2020, quatro secretários especiais de cultura foram nomeados no Brasil. Outras mudanças se estendem às chefias das demais secretarias vinculadas à Secretaria Especial de Cultura - como a Secretaria do Audiovisual, Secretaria de Fomento e Incentivo à Cultura e a Secretaria de Diversidade Cultural. Ademais, nesse período ocorreram cancelamentos de editais ${ }^{3}$ e redução nas chamadas de editais da Ancine (Agência Nacional do Cinema) de 30, em 2018, para 2, em 2019. Esses acontecimentos impactam fortemente sobre os projetos culturais. As mudanças constantes de comando impedem, por exemplo, a continuidade de projetos, principalmente de médio prazo. A ausência de uma agenda de políticas definida, objetiva e contínua, para o referido setor gera um cenário de instabilidade. Mudanças de tamanha profundidade se propagam para além do setor cultural. Diante do exposto, estudos que busquem mensurar como o setor cultural afeta a sociedade tornam-se extremamente relevantes. O objetivo deste estudo é analisar os impactos de choques no consumo de bens e serviços do setor cultural sobre a produção, o rendimento e o emprego do próprio setor e sobre a economia em geral. Para tanto, é utilizado o modelo de insumo-produto e calculado os multiplicadores de produção, renda e emprego, bem como os geradores de renda e emprego, com base na matriz de insumo-produto, elaborada pelo Instituto Brasileiro de Geografia e Estatística (IBGE).

A perspectiva de que um elevado dinamismo no setor cultural é um importante impulsionador de desenvolvimento econômico e social já foi defendida em alguns estudos (Alper; Wassall, 2006; Markusen; Schrock,

$2 \bigcirc$ fato de a nova lei estipular um percentual maior de ingressos gratuitos possivelmente se traduzirá na elevação dos preços dos ingressos padrões.

3 Foram suspensos editais da Ancine e do Fundo de Apoio à Cultura (FAC). 
2006; Silva, 2007). Ainda que esta análise seja puramente econômica, ela contribui para a literatura na medida em que dá uma dimensão do valor mínimo desse setor. Com tal informação, é possível discutir se, e como, o suporte do governo para as atividades culturais pode ser benéfico para a sociedade. Apesar de no presente estudo não ser possível abordar as diversas faces do processo de desenvolvimento advindo do setor cultural, na medida em que se investigam renda e trabalho em alguma medida é ponderado o bem-estar social.

Observando a integração da população com as indústrias culturais, o Sistema de Indicadores de Percepção Social (SIPS) sobre cultura para o ano de 2010, desenvolvido pelo Instituto de Pesquisa Econômica Aplicada (Ipea), indica que os principais obstáculos para o acesso à oferta cultural são: os preços elevados, a barreira social imposta pelo perfil do público que frequenta espaços culturais e a localização dos equipamentos culturais. Em 2010, 71\% dos brasileiros concordaram com a afirmação de que os altos preços representavam uma barreira à fruição de bens culturais; $62,6 \%$ dos entrevistados identificaram os equipamentos culturais como distantes de sua residência; e $56 \%$ concordam que existe uma barreira no acesso à cultura associada ao perfil do consumidor típico desses bens (Codes; Silva; Araújo, 2011).

Outros estudos apontam que os baixos níveis de consumo de cultura no Brasil estão possivelmente mais relacionados ao hábito de consumo de tais bens e serviços, do que à ausência de tempo ou de recursos monetários (Machado et al., 2017). O denominador comum é que a distribuição cultural no Brasil é desigual (Codes; Silva; Araújo, 2011; Machado et al., 2017; Machado; Paglioto; Bruzzi De Carvalho, 2018; Machado; Simões; Diniz, 2013).

O setor cultural brasileiro é composto por três agentes essenciais: produtor, exibidor e consumidor. Ademais, o governo tem um papel fundamental de atuar delimitando as leis de incentivo à cultura. A interação entre tais agentes é o que define a rentabilidade do ramo. $O$ setor cultural gera empregos diretos e indiretos (Machado; Rabelo; Moreira, 2013). Refletir, portanto, sobre o referido setor à luz dos impactos advindos das mudanças ocorridas no setor cultural faz-se importante no atual contexto. Apesar de o mercado de trabalho brasileiro ter apresentado indicativos mais favoráveis em termos de geração de emprego em 2019, a despeito dos baixos indicadores de atividade econômica nacional, essa força de tra- 
balho é permeada por altos contingentes de desocupados, desalentados e subocupados (Lameiras et al., 2019). Observar a movimentação do setor cultural, considerando os seus efeitos sobre o mercado de trabalho brasileiro, torna-se, portanto, uma questão de pesquisa relevante.

O artigo está estruturado em seis seções, incluindo esta introdução. $\mathrm{Na}$ seção dois é feita uma contextualização teórica sobre consumo e fruição de cultura. Na seção subsequente, a base de dados utilizada é explicada, bem como todo o tratamento que esta recebeu. Na quarta seção a estratégia empírica é apresentada, enquanto os resultados obtidos são expostos na seção cinco. A última seção traz as considerações finais.

\section{Contextualização teórica}

Para Cunha e Britto (2017), Furtado (1999) atribui um papel crucial à cultura para o processo de desenvolvimento da América Latina, ampliando as análises estritamente econômicas. Furtado teoriza sobre a economia do desenvolvimento atribuindo à cultura local o papel de variável-chave para explicar a dinâmica do desenvolvimento:

O processo de globalização da cultura tende a acelerar-se. Ao mesmo tempo, todos os povos aspiram a ter acesso ao patrimônio comum da humanidade, o qual se enriquece permanentemente. Resta saber quais são os povos que continuarão a contribuir para esse enriquecimento e quais aqueles que serão relegados ao papel passivo de simples consumidores de bens culturais adquiridos nos mercados. (Furtado, 1999, p. 66-67)

Tendo em vista essa perspectiva, é importante compreender como o suporte do governo pode auxiliar nesse processo de desenvolvimento de uma sociedade, via setor cultural. Na literatura internacional, Baumol e Bowen (1966), examinando o setor de teatros e de apresentações ao vivo na Broadway, argumentaram a importância do subsídio às artes. $\bigcirc$ fato determinante para a existência de tal subsídio está na perspectiva de que as referidas atividades são intensivas em trabalho. Nesse sentido, para os autores, diferentemente de setores com uso intensivo de tecnologia - caracterizados por ganhos de produtividade e redução dos custos -, as organizações culturais se deparam com a impossibilidade de ganhos de produtividade. Os custos relativos progressivamente maiores nas artes performáticas estão atrelados à limitação de reprodução indefinida do espetáculo, à falta de retorno financeiro para cobrir certos custos em espetáculos com curto 
período de exibição, e à impossibilidade de os preços dos ingressos acompanharem os custos.

Baumol e Bowen (1966) e Baumol (1996) destacam que, nas organizações de artes, o rendimento proveniente das vendas muitas vezes fica aquém dos custos. Assim, apresentam o problema do cost disease, segundo o qual a falta de ganhos de produtividade nas artes de espetáculo (performáticas) resulta em constante aumento dos custos.

A crítica ao problema de cost disease diz respeito ao questionamento da existência de custos crescentes nos setores culturais. Nesse sentido, Cowen (1996) busca justificar o motivo pelo qual não se deve acreditar no cost disease, argumentando que as artes performáticas não são estagnadas em termos de produtividade, em comparação com outros setores econômicos. Como as artes performáticas desfrutam de inovações no processo e inovações no produto, a produtividade do setor se eleva ao longo dos anos (Cowen, 1996).

Fatores como a reprodução eletrônica tornam as artes performáticas mais produtivas no processo se a produtividade é medida em termos de unidades de consumo. Assim, uma dada performance pode atingir um maior número de consumidores. Em relação à inovação no produto, a criatividade do trabalho humano desafia a lógica do argumento do cost disease, na medida em que os artistas contribuem para a produtividade, gerando novas ideias ou usando o seu capital humano. Por exemplo, a crescente diversidade da composição musical pode representar um grande aumento da produtividade (Cowen, 1996). Em síntese, se o argumento do cost disease está restrito aos bens de produtividade constante, em geral, ele não teria relevância para setor das artes performáticas, quando considerado o crescimento no longo prazo.

Para Besharov (2005), a hipótese de cost disease não aborda devidamente o desenvolvimento de uma análise de bem-estar para apoiar o argumento do suporte do governo para as artes. Para o autor, o problema de cost disease, nem sistematicamente, nem formalmente, demonstra como os indivíduos estariam numa situação melhor ou pior, em decorrência do apoio governamental ao setor de atividades artísticas. Ademais, para Besharov (2005), o estudo de Baumol e Bowen (1966) não considera a possibilidade de que as gerações futuras possam desejar, por exemplo, que o governo aloque gastos de uma forma diferente, digamos, em segurança. 
Apesar de essas perspectivas sinalizarem para as limitações da alocação de recursos públicos para o setor cultural, nenhuma delas consegue refutar a potencial capacidade desencadeadora de desenvolvimento em outros setores que a indústria cultural apresenta. A atividade cultural tem o potencial de gerar empregos e renda em uma sociedade, efeitos que podem transbordar para outras atividades econômicas (Florida, 2005; Markusen; Schrock, 2006; Vivant, 2012). O setor das artes performáticas, por exemplo, é comumente assumido como resultando em "bens mistos" que têm características de bens públicos, isto é, carregam benefícios para as gerações futuras, prestígio e educação.

Conhecendo as peculiaridades atinentes ao mercado de trabalho cultural é possível obter uma compreensão mais ampla da capacidade de repercussão do referido setor na economia. O mercado de trabalho cultural possui especificidades já registradas na literatura, Benhamou (2003) ressalta as suas heterogeneidades. Segundo a autora, trata-se de um mercado de trabalho atípico e não-competitivo, caracterizado pelo fato de que os artistas são substitutos imperfeitos entre si. Consequentemente, em cenários específicos, é possível que os preços dos bens culturais aumentem, e esse aumento não conduza a uma redução da demanda. A despeito de tais especificidades, para ela é possível que a oferta de trabalho artística possua efeitos multiplicadores na economia de uma localidade que ultrapassam o ramo cultural. Neste contexto, para Markusen e Schrock (2006), o trabalho dos artistas cria opções de entretenimento, estimulando a arte local, permitindo que a renda gerada circule, estimulando a economia.

Alguns estudos que analisam o setor cultural à luz do método de insumo-produto, ainda que pouco frequentes, podem ser encontrados na literatura internacional. Bryan et al. (2000) examina o impacto econômico das artes e da indústria cultural sobre a economia galesa, com enfoque principal sobre o produto, emprego e renda. Tohmo (2005), com uma abordagem similar, investiga os impactos na produção, demanda, salários, emprego e impostos nacionais e regionais do Festival de Música Folclórica Kaustinen, na Finlândia. Bowitz e Ibenholt (2009), por sua vez, entre outros pontos, analisam o impacto econômico de investimentos em projetos voltados para o fomento de patrimônio cultural. Este último estudo, considerando atividades culturais e turísticas, discute as possibilidades de mensuração de diferentes tipos de impactos econômicos, direto e indireto, de investimento em cultura. 
Alguns estudos que focam no consumo e fruição de bens e serviços culturais destacam o impacto do consumo desses bens e serviços sobre resultados socioeconômicos, como, educação, saúde e desenvolvimento econômico (Berg; Zia, 2017; DellaVigna; La Ferrara, 2015; La Ferrara; Chong; Duryea, 2012; Vaughan et al., 2000). DellaVigna e La Ferrara (2015) fazem uma análise teórica dos estudos que abordam o impacto da exposição à mídia em variáveis como educação, escolhas familiares, decisões de trabalho e migração, escolhas ambientais, saúde, crime, economia pública, atitudes, consumo, poupança e desenvolvimento econômico.

Os autores percebem, entre outros pontos, que para quase todas as tipologias consideradas de mídia, a demanda dos consumidores por conteúdo de mídia surge, em grande parte, devido à demanda por entretenimento, com os impactos econômicos emergindo como um subproduto. Eles ressaltam, por exemplo, que as crianças assistem televisão pelo seu valor de divertimento, e não pensando em possíveis impactos sobre educação. Consequentemente, a seleção de uma mídia específica é provavelmente não relacionada com a preferência por determinados resultados econômicos - a dizer, educação, crime violento ou fertilidade. O papel primordial da demanda por entretenimento se reflete no fato de que as pessoas gastam grande parte do tempo em entretenimento.

Os efeitos sobre resultados familiares, tais como fertilidade, planejamento familiar, postergação do casamento, são os casos mais referenciados dos impactos substanciais da mídia (Chong; La Ferrara, 2009; La Ferrara; Chong; Duryea, 2012; Vaughan et al., 2000). Há evidências de que a exposição a um comportamento particular na televisão muda o comportamento da plateia (DellaVigna; La Ferrara, 2015). Nesse sentido, La Ferrara et al. (2012) estimam o efeito das novelas sobre as taxas de fertilidade no Brasil. Para identificar os efeitos da exposição aos programas da rede Globo na fertilidade, La Ferrara et al. (2012) usam uma estratégia de diff in diff, explorando a entrada escalonada da Globo em diferentes áreas municipais. Combinando os dados censitários com aqueles sobre a localização da antena de estações Globo, eles descobriram que a exposição ao sinal Globo diminuiu a probabilidade de dar à luz em 0,5 pontos percentuais. Ademais, tal efeito não é acionado por pré-tendências, dado que a redução na fecundidade começa exatamente um ano após a entrada da Globo na área. Em outro estudo, examinando o impacto das novelas brasileiras sobre o divórcio, Chong e La Ferrara (2009), por 
meio da mesma estratégia de diff in diff, notam que as taxas de separação e divórcio aumentam em municípios cobertos pelo sinal da Globo nos anos após a chegada da rede.

Bursztyn e Cantoni (2016) e Berg e Zia (2017), por meio de abordagens quantitativas distintas, sugerem que a informação e os comportamentos retratados na televisão podem afetar as escolhas de consumo e de poupança, não apenas através da publicidade mas possivelmente também através da imitação de modelos. Fica perceptível que, apesar da vasta literatura, a compreensão de como choques no consumo de bens culturais afetam o setor e desencadeia efeitos sobre os outros setores ainda parece ser uma questão que merece ser mais discutida, especialmente no Brasil.

$\mathrm{Na}$ literatura nacional, os aspectos teóricos propostos por Florida (2002), quanto à relevância da qualificação (talento) e diversidade na formação dos trabalhadores do setor cultural para a sociedade e, por conseguinte, para o desenvolvimento das cidades, é um tema recorrente. Nesse contexto, Golgher (2011), com dados em painel para os anos de 1991 e 2000, identifica uma relação direta entre elevados índices de entretenimento e maiores proporções de indivíduos qualificados nas regiões metropolitanas brasileiras.

Jäger (2014), por sua vez, discute a necessidade da correta mensuração das atividades econômicas que compõem a economia criativa, dada sua importância para a geração de emprego e renda. Considerando uma sequência de variáveis relacionadas às dimensões talento, diversidade e tecnologia, ele constrói o Índice da Economia Criativa Brasileiro (IECBr) e nota que os municípios que concentram os melhores indicadores são os pertencentes as regiões Sul e Sudeste.

Machado et al. (2017) discutem a alocação de tempo e o consumo de bens e serviços culturais no Brasil, com base nos dados da Pesquisa de Orçamentos Familiares (POF) e da Pesquisa Nacional por Amostra de Domicílios (PNAD). Os principais resultados sugerem que escolaridade e participação no mercado de trabalho afetam o gasto em consumo cultural, e a disponibilidade de tempo é positivamente correlacionada com tal consumo.

Fica perceptível que a literatura nacional ainda possui lacunas a serem preenchidas, especialmente no que diz respeito à capacidade do setor cultural de fomentar a economia de uma localidade. Com a compreensão mais ampla da importância do setor cultural, do ponto de vista da geração de renda e empregos no Brasil, torna-se possível pensar políticas públicas 
de qualidade, atreladas ao ramo artístico cultural, com potencial de subsidiar o desenvolvimento econômico do país.

\section{Fonte e tratamento dos dados}

Para a realização deste estudo foi utilizada a Matriz de Insumo-Produto, referente ao ano 2015, elaborada pelo IBGE, a partir das Tabelas de Recursos e Usos (TRU). A construção da matriz segue as recomendações do manual internacional System of National Accounts, das Nações Unidas, que apresenta um conjunto de recomendações para a compilação de medidas de atividade econômica, internacionalmente aceito (IBGE, 2018). No Brasil, as informações sobre produção/produtos e setores da economia são apresentadas seguindo a nomenclatura do Sistema de Contas Nacionais, sendo a principal fonte de dados para a construção da matriz de insumo-produto a Pesquisa Industrial Anual - Empresa (PIA-Empresa). A estrutura básica de uma matriz de insumo-produto é exibida no Quadro 1, a seguir.

Quadro 1 Tabela de Insumo-Produto simplificada para uma economia com dois setores

\begin{tabular}{l|r|r|r|r|r|r|r}
\hline & $\begin{array}{r}\text { Setor } \\
\mathbf{1}\end{array}$ & $\begin{array}{r}\text { Setor } \\
\mathbf{2}\end{array}$ & $\begin{array}{r}\text { Consumo } \\
\text { das } \\
\text { Famílias }\end{array}$ & Governo & $\begin{array}{r}\text { Investi- } \\
\text { mento }\end{array}$ & $\begin{array}{r}\text { Expor- } \\
\text { tações }\end{array}$ & Total \\
\hline Setor 1 & $Z_{11}$ & $Z_{12}$ & $C_{1}$ & $G_{1}$ & $I_{1}$ & $E_{1}$ & $X_{1}$ \\
\hline Setor 2 & $Z_{21}$ & $Z_{22}$ & $C_{2}$ & $G_{2}$ & $I_{2}$ & $E_{2}$ & $X_{2}$ \\
\hline Importação & $M_{1}$ & $M_{2}$ & $M_{c}$ & $M_{g}$ & $M_{i}$ & & $M$ \\
\hline Impostos & $T_{1}$ & $T_{2}$ & $T_{c}$ & $T_{g}$ & $T_{i}$ & $T_{e}$ & $T$ \\
\hline VA & $W_{1}$ & $W_{2}$ & & & & & $W$ \\
\hline Total & $X_{1}$ & $X_{1}$ & $C$ & $G$ & $I$ & $E$ & \\
\hline Ocupação & $O_{1}$ & $O_{2}$ & & & & & \\
\hline
\end{tabular}

Fonte: Adaptado de Miller e Blair (2009).

As variáveis do Quadro 1 apresentam um conjunto de dados com valores monetários de transação entre os agregados, para um determinado ano. A matriz $Z_{12}$, por exemplo, aponta a demanda por insumos do setor 2 adquiridos do setor 1 , ou, em outras palavras, a venda de insumo do setor 1 para o setor 2 . As importações, $M$, representam o valor monetário de bens e serviços importados utilizados como insumos pelos setores. Os impostos, $T$, 
representam todos os impostos, livres de subsídios, que incidem sobre os bens e serviços e sobre os demais componentes da demanda final (consumo das famílias, governo, investimento e exportações). O valor adicionado (VA) é composto pelas remunerações (salários e contribuições sociais) e pelo excedente operacional bruto. Já as ocupações, $O$, são os postos de trabalho utilizados pelas atividades produtivas no ano.

As informações referentes às relações intersetoriais $(Z)$ e à demanda final foram obtidas por meio da matriz de insumo-produto. Já os dados de importações, impostos, valor adicionado e ocupações estão disponibilizados nas tabelas de recursos e usos, sendo ambos os dados compilados pelo IBGE. Vale destacar que as informações não sombreadas no Quadro 1 são aquelas desnecessárias para os propósitos deste estudo, uma vez que todas as técnicas aqui utilizadas não fazem uso desses dados.

$\mathrm{Na}$ matriz de insumo-produto, com 67 setores, disponibilizada pelo IBGE, é possível identificar o setor de "atividades artísticas, criativas e de espetáculos"4. Tal como observado anteriormente, os setores da matriz de insumo-produto são compilados segundo a nomenclatura no Sistema de Contas Nacionais. Esta, por sua vez, agrega as atividades segundo a Classificação Nacional de Atividades Econômicas, versão 2.0 (CNAE 2.0).

A organização hierárquica da CNAE 2.0 é baseada numa estrutura com cinco níveis, 21 seções, 87 divisões, 285 grupos, 673 classes e 1.301 subclasses. O setor de atividades artísticas, criativas e de espetáculos do Sistema de Contas Nacionais é equivalente à seção R (artes, cultura, esporte e recreação) da CNAE 2.0. A seção $R$, por sua vez, engloba quatro divisões: a) atividades artísticas, criativas e de espetáculos; b) atividades ligadas ao patrimônio cultural e ambiental; c) atividades de exploração de jogos de azar e apostas; e d) atividades esportivas e de recreação e lazer. Na Tabela 1 é apresentada a correspondência entre o setor de atividades artísticas, criativas e de espetáculos e a estrutura detalhada dos códigos da CNAE 2.0.

Cabe denotar que, tal como descrito anteriormente, o setor de atividades artísticas, criativas e de espetáculos engloba quatro divisões da CNAE 2.0, sendo uma delas identificada como atividades artísticas, criativas e de espetáculos. Uma vez que o SCN e a CNAE 2.0 são duas classificações diferentes, esses agrupamentos, apesar de exibirem o mesmo nome, não são equivalentes.

4 Por vezes, ao longo do texto, o setor de atividades artísticas, criativas e de espetáculos é tratado apenas por setor cultural. 
Tabela 1 Estrutura detalhada dos códigos da CNAE 2.0 correspondente ao setor de Atividades artísticas, criativas e de espetáculos

\begin{tabular}{|c|c|c|c|}
\hline $\begin{array}{l}\text { Gru- } \\
\text { po }\end{array}$ & Classe & Subclasse & Denominação \\
\hline & & & ATIVIDADES ARTÍSTICAS, CRIATIVAS E DE ESPETÁCULOS \\
\hline \multirow[t]{14}{*}{90.0} & & & Atividades artísticas, criativas e de espetáculos \\
\hline & $90.01-9$ & & Artes cênicas, espetáculos e atividades complementares \\
\hline & & $9001-9 / 01$ & Produção teatral \\
\hline & & $9001-9 / 02$ & Produção musical \\
\hline & & $9001-9 / 03$ & Produção de espetáculos de dança \\
\hline & & $9001-9 / 04$ & Produção de espetáculos circenses, de marionetes e similares \\
\hline & & $9001-9 / 05$ & Produção de espetáculos de rodeios, vaquejadas e similares \\
\hline & & $9001-9 / 06$ & Atividades de sonorização e de iluminação \\
\hline & & $9001-9 / 99$ & $\begin{array}{l}\text { Artes cênicas, espetáculos e atividades complementares não } \\
\text { especificados anteriormente }\end{array}$ \\
\hline & $90.02-7$ & & Criação artística \\
\hline & & $9002-7 / 01$ & Atividades de artistas plásticos, jornalistas independentes e escritores \\
\hline & & $9002-7 / 02$ & Restauração de obras de arte \\
\hline & $90.03-5$ & $9003-5 / 00$ & $\begin{array}{l}\text { Gestão de espaços para artes cênicas, espetáculos e outras } \\
\text { atividades artísticas }\end{array}$ \\
\hline & & & ATIVIDADES LIGADAS AO PATRIMÔNIO CULTURAL E AMBIENTAL \\
\hline \multirow[t]{7}{*}{91.0} & & & Atividades ligadas ao patrimônio cultural e ambiental \\
\hline & $91.01-5$ & $9101-5 / 00$ & Atividades de bibliotecas e arquivos \\
\hline & $91.02-3$ & & $\begin{array}{l}\text { Atividades de museus e de exploração, restauração artística e } \\
\text { conservação de lugares e prédios históricos e atrações similares }\end{array}$ \\
\hline & & $9102-3 / 01$ & $\begin{array}{l}\text { Atividades de museus e de exploração de lugares e prédios históricos } \\
\text { e atrações similares }\end{array}$ \\
\hline & & $9102-3 / 02$ & Restauração e conservação de lugares e prédios históricos \\
\hline & $91.03-1$ & $9103-1 / 00$ & $\begin{array}{l}\text { Atividades de jardins botânicos, zoológicos, parques nacionais, } \\
\text { reservas ecológicas e áreas de proteção ambiental }\end{array}$ \\
\hline & & & ATIVIDADES DE EXPLORAÇÃO DE JOGOS DE AZAR E APOSTAS \\
\hline \multirow[t]{5}{*}{92.0} & & & Atividades de exploração de jogos de azar e apostas \\
\hline & $92.00-3$ & & Atividades de exploração de jogos de azar e apostas \\
\hline & & $9200-3 / 01$ & Casas de bingo \\
\hline & & $9200-3 / 02$ & Exploração de apostas em corridas de cavalos \\
\hline & & $9200-3 / 99$ & $\begin{array}{l}\text { Exploração de jogos de azar e apostas não especificados anterior- } \\
\text { mente }\end{array}$ \\
\hline
\end{tabular}


Tabela 1 (continuação)

\begin{tabular}{|c|c|c|c|}
\hline $\begin{array}{l}\text { Gru- } \\
\text { po }\end{array}$ & Classe & Subclasse & Denominação \\
\hline & & & ATIVIDADES ESPORTIVAS E DE RECREAÇÃO E LAZER \\
\hline \multirow[t]{7}{*}{93.1} & & & Atividades esportivas \\
\hline & $93.11-5$ & $9311-5 / 00$ & Gestão de instalações de esportes \\
\hline & $93.12-3$ & $9312-3 / 00$ & Clubes sociais, esportivos e similares \\
\hline & 93.13-1 & $9313-1 / 00$ & Atividades de condicionamento físico \\
\hline & 93.19-1 & & Atividades esportivas não especificadas anteriormente \\
\hline & & $9319-1 / 01$ & Produção e promoção de eventos esportivos \\
\hline & & 9319-1/99 & Outras atividades esportivas não especificadas anteriormente \\
\hline \multirow[t]{8}{*}{93.2} & & & Atividades de recreação e lazer \\
\hline & $93.21-2$ & $9321-2 / 00$ & Parques de diversão e parques temáticos \\
\hline & $93.29-8$ & & Atividades de recreação e lazer não especificadas anteriormente \\
\hline & & $9329-8 / 01$ & Discotecas, danceterias, salões de dança e similares \\
\hline & & $9329-8 / 02$ & Exploração de boliches \\
\hline & & $9329-8 / 03$ & Exploração de jogos de sinuca, bilhar e similares \\
\hline & & $9329-8 / 04$ & Exploração de jogos eletrônicos recreativos \\
\hline & & $9329-8 / 99$ & $\begin{array}{l}\text { Outras atividades de recreação e lazer não especificadas anterior- } \\
\text { mente }\end{array}$ \\
\hline
\end{tabular}

Fonte: Elaboração própria com base na CNAE 2.0 (IBGE, 2007).

\section{Estratégia empírica}

O modelo de insumo-produto, em sua forma básica, exibe os fluxos monetários decorrentes da distribuição dos bens e serviços utilizados como insumo industrial e destinados à demanda final, por meio de um sistema de equações lineares. Em um processo produtivo, incluindo, evidentemente, a prestação de um serviço, os setores da economia produzem bens (produto), fazendo uso de um conjunto de bens de outros setores (insumos). O modelo de insumo-produto fundamenta-se, portanto, nos fluxos de bens e serviços de cada setor produtor para os setores consumidores (Miller; Blair, 2009).

A relação entre os setores, estabelecida pela compra e venda de insumos, cria um sistema de interdependência, exibida por meio de uma tabela de transações interindustriais $(z)$. Ainda que um setor possa exibir uma 
demanda limitada por insumos, sua atividade pode ter um efeito indireto amplo na economia, justificada pela relação de interdependências entre os setores. Cada setor $i$ tem seu produto ou serviço demandado por outros setores $j$, utilizando-o enquanto insumo, ou para ser consumido pelos outros componentes da demanda final $(f)$. Assim, é possível a construção de um sistema de equações, com a economia classificada em $n$ setores:

$$
\begin{aligned}
& x_{1}=z_{11}+z_{12}+\ldots+z_{1 n}+f_{1} \\
& \vdots \\
& x_{n}=z_{n 1}+z_{n 2}+\ldots+z_{n n}+f_{n}
\end{aligned}
$$

onde $x_{n}$ corresponde à produção total do enésimo setor, $z_{i j}$ é a produção do setor $i$ utilizada como insumo pelo setor $j$, e $f_{n}$ sintetiza a demanda final, composta pelo consumo das famílias, investimento, gastos do governo e exportações, sendo todas as informações expressas em valores monetários.

O modelo de insumo-produto assume que a produção de um determinado bem ou serviço utiliza uma proporção fixa de insumos intermediários, dessa forma, tem-se:

$$
a_{i j}=\frac{z_{i j}}{x_{j}}
$$

Essa razão, chamada de coeficiente técnico, indica o valor em reais dos insumos do setor $i$ necessário para produção do setor $j$. Da equação anterior, tem-se:

$$
z_{i j}=a_{i j} x_{j}
$$

Substituindo essa expressão na equação (1) e rearranjando-a:

$$
\begin{aligned}
& x_{1}-a_{11} x_{1}-a_{12} x_{2}-\ldots-a_{1 n} x_{n}=f_{1} \\
& \vdots \quad \vdots \quad \vdots \\
& x_{n}-a_{n 1} x_{1}-a_{n 2} x_{2}-\ldots-a_{n n} x_{n}=f_{n}
\end{aligned}
$$

Dessa forma, se a demanda final por um determinado setor se modifica, é possível inferir sobre a quantidade de insumos necessários para satisfazer essa nova demanda. A equação (4) pode ser escrita como: 


$$
\begin{array}{ccc}
\left(1-a_{11}\right) x_{1}-a_{11} x_{1}-a_{12} x_{2}-\cdots-a_{1 n} x_{n}=f_{1} \\
\vdots & \vdots & \vdots \\
-a_{n 1} x_{1}-a_{n 2} x_{2}-\cdots-\left(1-a_{n n}\right) x_{n}=f_{n}
\end{array}
$$

Escrevendo (5) na sua forma matricial, tem-se:

$$
(I-A) x=f
$$

em que $I$ é uma matriz identidade; $A$ é uma matriz $(n \times n)$ de coeficientes técnicos; $x$ é um vetor com o valor da produção para os $n$ setores; e $f$ é um vetor de dimensão $n$ com os valores da demanda final, por setor. Por meio de algumas operações com matrizes, tem-se:

$$
\begin{aligned}
& (I-A)^{-1}(I-A) x=(I-A)^{-1} f \\
& I x=(I-A)^{-1} f \\
& x=(I-A)^{-1} f
\end{aligned}
$$

onde $(I-A)^{-1}$ é conhecida como inversa de Leontief ou matriz de efeitos diretos e indiretos.

\subsection{Multiplicador de produção}

A partir da equação (7), um primeiro exercício é mensurar o impacto que mudanças na demanda final de um setor, em específico, o setor de atividades artísticas, criativas e de espetáculos, exercem sobre o próprio setor e sobre a economia. Cabe notar que o efeito de um aumento hipotético no consumo das famílias, por exemplo, sobre o consumo de bens culturais, não se restringe apenas ao valor do aumento e ao referido setor. Como os modelos de insumo-produto captam as relações de interdependência setorial, o impacto é sentido em toda a economia. Tem-se, portanto:

$$
\Delta x=(I-A)^{-1} \Delta f
$$

onde, por meio do vetor $\Delta f$, em seu j-ésimo setor, seria inserida a mudança desejada. $O$ vetor $\Delta x$ capta tal mudança por setor e o efeito total sobre a 
economia por meio de $\sum_{j=1}^{n} x_{j}$. O valor do aumento na demanda final tem seu efeito inicial restrito ao setor que sofreu o choque.

Assumindo que a inversa de Leontif é $(I-A)^{-1}=l$, obtém-se o conhecido multiplicador de produção, por meio de $m_{j}=\sum_{i=1}^{n} l_{i j}$. O multiplicador de produção capta o efeito direto sobre a economia causado pela mudança da produção do setor que sofre o choque, enquanto o efeito indireto compreende o impacto dessa mudança sobre os demais setores, dada a necessidade de aquisição de insumos e comercialização dos produtos devido ao choque inicial. Nesse sentido, é evidente que o setor mais beneficiado sempre será o próprio setor que sofreu o "choque", seguido por aqueles setores fornecedores de insumos e, por fim, os demais setores da economia.

\subsection{Gerador e multiplicador de emprego e renda}

As mudanças na demanda final, por exemplo, decorrentes do aumento no consumo das famílias ou do incremento dos investimentos públicos em um determinado setor, têm um efeito amplo sobre a economia. Inicialmente, foram observados os impactos dessa mudança hipotética sobre a produção dos setores. Outras duas análises que o modelo de insumo-produto proporciona está nos efeitos que mudanças na demanda final exercem sobre o nível de emprego e sobre o rendimento dos trabalhadores.

Seja $e_{i}$ o coeficiente de emprego, obtido pela razão entre o emprego total no setor $j$ e o valor total da produção do setor $j$. A partir da inversa de Leontif e, novamente, fazendo $(I-A)^{-1}=l$, pode-se construir a seguinte expressão:

$$
G E_{j}=\sum_{i=1}^{n} l_{i j} e_{i}
$$

onde $G E_{j}$ é o gerador de empregos, e $l_{i j}$ o $i j$-ésimo elemento da matriz inversa de Leontief. $O$ gerador de empregos evidencia o número de empregos criados em cada setor, devido à variação de uma unidade, em valor monetário, na demanda final. Cabe destacar que o método permite a mudança simultânea no valor produzido de todos os setores, possibilitando observar uma infinita combinação de diferentes mudanças em qualquer componente de demanda final. 
O multiplicador de emprego, por sua vez, é dado pela razão entre o gerador de empregos, para cada setor, e o seu respectivo coeficiente de emprego. O referido multiplicador é, portanto, um indicativo de quantos empregos são gerados, direta e indiretamente, para cada novo emprego criado no setor $j$ (Guilhoto; Sesso Filho, 2010):

$$
M E_{j}=\frac{G E_{j}}{e_{i}}
$$

De maneira análoga ao gerador de empregos, o gerador de renda pode ser calculado por:

$$
G R_{j}=\sum_{i=1}^{n} l_{i j} r_{i}
$$

onde $G R_{j}$ é o gerador de renda, e $r_{i}$ é o coeficiente de renda, calculado pela razão entre o rendimento total das famílias proveniente do setor $j$ e o valor total da produção do setor $j$. A equação (11) permite observar a renda familiar adicional gerada no setor $j$, por meio da remuneração dos seus trabalhadores, dado um aumento de demanda final nos setores da economia. Já o multiplicador de renda, que indica a mudança na renda da economia ocasionada pela redução na renda no setor $j$, é dado pela razão entre o gerador de renda, para cada setor, e o seu respectivo coeficiente de renda:

$$
M R_{j}=\frac{G R_{j}}{r_{i}}
$$

\section{Análise e discussão dos resultados}

Com o intuito de analisar a importância do setor criativo no Brasil, empregou-se o modelo de insumo-produto. Esse procedimento metodológico permite observar se, e como, alterações no nível de consumo de bens e serviços do setor cultural estão associadas a modificações no nível de emprego, renda e produção nos demais setores econômicos.

Antes de entrar na discussão dos resultados dos multiplicadores de produto, renda e emprego, cabe apresentar alguns dados presente na matriz de insumo-produto. Observando a estrutura de insumo-produto, o setor 
de atividades artísticas, criativas e de espetáculos teve $23,7 \%$ da sua produção destinada ao fornecimento de insumos, incluído o próprio setor. Os setores que mais demandaram do setor cultural, em 2015, foram as "atividades de televisão, rádio, cinema e gravação/edição de som e imagem", com $28,4 \%$ da oferta de serviços culturais destinados a essa atividade, e as "organizações associativas e outros serviços pessoais", com $16,2 \%$. Este último setor compreende, entre outros, as "outras atividades de serviços pessoais", por exemplo, sindicatos e organizações associativas, organizações em defesa de diretos sociais e agências matrimoniais.

Além de ofertar seus bens e serviços para serem utilizados como insumo, a atividade cultural também é demandada pelos demais componentes da demanda final. Nesse sentido, destaca-se a importância do consumo das famílias para o setor, com $71,4 \%$ de sua produção sendo destinada a esse grupo. Segundo dados da Pesquisa de Orçamento Familiar, 2002-2003, os dispêndios das famílias no setor cultural atingiram aproximadamente $3 \%$ do total de gastos familiares. Entre os principais itens de despesa cultural das famílias, destacam-se o consumo de audiovisual (cinema, tv a cabo, fotografia e outros), com 41,2\%, e leitura (livros, periódicos e outros), com 15,6\% dos gastos (Silva; Araújo; Souza, 2007).

Quando observado o setor cultural como demandante, é possível visualizar aqueles setores que mais fornecem insumos para essa atividade. Do total de gastos com insumos utilizados pelo setor cultural, 22,3\% correspondem às atividades imobiliárias, como a compra e aluguel de imóveis, e gestão e administração imobiliárias. A Tabela 2 exibe os cinco principais setores consumidores e fornecedores de insumos para as atividades artísticas, criativas e de espetáculos.

Conforme esperado, percebe-se uma estreita relação entre o setor cultural e algumas atividades-chaves no processo de difusão das práticas criativas. Por um lado, o setor cultural demanda espaços, técnicos, assessoria administrativa, jurídica e contábil para fornecer o bem final. Por outro lado, agora olhando para o canal de difusão do bem final, o consumo de bens culturais ocorre principalmente por meio de veículos de comunicação e entretenimento, como rádio, TV e cinema.

Os multiplicadores de produção visam determinar o impacto de variações nos componentes da demanda final sobre os diversos setores da economia. A definição do impacto, seja ele positivo ou negativo, depende dos objetivos do pesquisador e pode ser baseada em diversos fatores, como 
a existência de dados que comprovem um determinado aumento de demanda, um corte de investimento governamental em um setor, o possível aumento de exportações em razão de um novo acordo comercial, entre outros. Como pretende-se analisar a importância do setor cultural para a economia, por meio da influência que o setor exerce sobre a produção, o emprego e a renda do país, foi estabelecido como variação uma redução em $10 \%$ na demanda final pelo setor de atividades artísticas, criativas e de espetáculos. Esse valor corresponde a R $\$ 2.6$ bilhões, em 2015. Apenas a título de comparação, o orçamento previsto do então Ministério da Cultura, segundo de lei que fixa a despesa da União para o exercício financeiro de 2019, foi de R $\$ 2.8$ bilhões (BRASIL, 2019). Quando considerados os gastos totais das três esferas governamentais (federal, estadual e municipal), o montante alocado no setor cultural aumentou de R $\$ 7,1$ bilhões, em 2011, para $\mathrm{R} \$ 9,1$ bilhões em 2018. Apesar desse incremento, a participação dos gastos no setor cultural como proporção dos gastos totais reduz de $0,28 \%$ para $0,21 \%$, no referido intervalo (IBGE, 2019).

Tabela 2 Principais setores consumidores e fornecedores de insumos para o setor cultural

\begin{tabular}{lrrr}
\hline Fornecedores para o setor cultural & R\$ Milhões & \% \\
\hline Atividades imobiliárias & 2910,46 & $22,33 \%$ \\
\hline Outras atividades profissionais, científicas e técnicas & 1442,95 & $11,07 \%$ \\
\hline Outras atividades administrativas e serviços complementares & 952,93 & $7,31 \%$ \\
\hline Atividades jurídicas, contábeis, consultoria e sedes de empresas & 933,27 & $7,16 \%$ \\
\hline Intermediação financeira, seguros e previdência complementar & 870,69 & $6,68 \%$ \\
\hline Consumidores para o setor cultural & $\mathbf{R \$}$ Milhões & $\%$ \\
\hline Atividades de televisão, rádio, cinema e gravação/edição de som & 2322,96 & $28,4 \%$ \\
e imagem & 1327,81 & $16,2 \%$ \\
\hline Organizações associativas e outros serviços pessoais & 802,33 & $9,8 \%$ \\
\hline Atividades artísticas, criativas e de espetáculos & 753,71 & $9,2 \%$ \\
\hline Administração pública, defesa e seguridade social & 573,84 & $7,0 \%$ \\
\hline Comércio por atacado e varejo & &
\end{tabular}

Fonte: Elaboração própria, com base na matriz de insumo-produto do Brasil - 2015.

Dado o choque na demanda final, por meio da redução no consumo de bens culturais, há inicialmente uma redução na produção do próprio setor, o que caracteriza o efeito direto do choque. A redução da necessidade de aquisição de insumos e comercialização dos produtos, devido ao choque, causa 
um efeito indireto sobre toda a economia. Esses efeitos são captados pelo multiplicador de produção. Os resultados apontam que uma redução de $10 \%$ no consumo das atividades artísticas, criativas e de espetáculos, resulta em um decréscimo de $\mathrm{R} \$ 2.7$ bilhões na produção do próprio setor, e $\mathrm{R} \$ 4.2$ bilhões no produto total brasileiro. A redução da produção, em milhões de reais, para os 10 setores que sofrem maior impacto é observada na Tabela 3. Sendo as atividades artísticas, criativas e de espetáculos tradicionalmente mais intensiva em serviços, são estes os setores que sofrem o maior impacto dado o choque proposto. As atividades imobiliárias, por exemplo, apresentam redução de $\mathrm{R} \$ 239$ milhões, equivalente a 5,7\% da redução total.

Tabela 3 Multiplicador de produção - Redução em 10\% na demanda final (2015)

\begin{tabular}{l|rr}
\hline Setores & $\begin{array}{r}\Delta \text { Produtos } \\
\text { R\$ milhões }\end{array}$ & $\begin{array}{r}\% \text { do } \\
\text { choque }\end{array}$ \\
\hline Atividades artísticas, criativas e de espetáculos & -2.710 & $64,4 \%$ \\
\hline Atividades imobiliárias & -239 & $5,7 \%$ \\
\hline Outras atividades profissionais, científicas e técnicas & -130 & $3,1 \%$ \\
\hline Intermediação financeira, seguros e previdência complementar & -115 & $2,7 \%$ \\
\hline Energia elétrica, gás natural e outras utilidades & -106 & $2,5 \%$ \\
\hline Atividades jurídicas, contábeis, consultoria e sedes de empresas & -101 & $2,4 \%$ \\
\hline Outras atividades administrativas e serviços complementares & -96 & $2,3 \%$ \\
\hline Comércio por atacado e varejo & -95 & $2,3 \%$ \\
\hline Atividades de televisão, rádio, cinema e gravação/edição de som & -58 & $1,4 \%$ \\
e imagem & -49 & $1,2 \%$ \\
\hline Transporte terrestre & &
\end{tabular}

Fonte: Elaboração própria com base na matriz de insumo-produto do Brasil - 2015.

A redução na demanda por bens culturais implica, por exemplo, menos espaços locados para sets de filmagem, apresentações teatrais e exibição de exposições. Da mesma forma, há redução na necessidade de contratação de seguros, na utilização de energia elétrica e no transporte de equipamentos. Portanto, o efeito resultante da queda da demanda do setor cultural é sentido em toda a economia.

É importante salientar que o efeito resultante observado sobre a produção não se restringe a um mero decréscimo do produto. Para além da redução do produto, há uma série de desdobramentos que podem ser traduzidos em perda de bem-estar social, afetando, por conseguinte, o processo 
de desenvolvimento nacional.

O modelo de insumo-produto também permite a observação do número de empregos necessários para satisfazer uma mudança hipotética na demanda final. Tal cálculo é feito por meio do gerador de empregos. Os resultados apresentados na Tabela 4 mostram que uma redução de 10\% na demanda das atividades artísticas, criativas e de espetáculos implica 77.176 empregos a menos nesse setor, o que significa redução de 8,5\% em seus postos de trabalho. Como o setor cultural utiliza diversos insumos, o choque em sua produção é sentido nos demais setores, reduzindo suas atividades. Consequentemente, com a menor atividade nos demais setores, reduz-se seus postos de trabalho, com perda adicional de 10.271 vagas, somando um total de 87.447 postos de trabalhos a menos na economia. Esses indicativos da capacidade da atividade cultural de gerar empregos dentro do setor e de seus efeitos multiplicadores corroboram os apontamentos da literatura (Florida, 2005; Machado; Simões; Diniz, 2013; Markusen; Schrock, 2006; Vivant, 2012). Essa redução de bem-estar não pode ser minimizada num país como o Brasil, marcado por outros sérios problemas, como a alta desigualdade de renda e de oportunidades; o elevado índice de criminalidade; e o desigual acesso a serviços básicos, como saúde e saneamento. Pensar que o setor artístico criativo pode ser colocado em segundo plano em termos de políticas públicas parece ser uma falácia, dados os significativos transbordamentos dos investimentos no setor.

Tabela 4 Efeito gerador de empregos - Redução em 10\% na demanda final (2015)

\begin{tabular}{l|r|r}
\hline Setores & $\begin{array}{r}\text { Redução no } \\
\text { emprego }\end{array}$ & $\begin{array}{r}\% \text { da } \\
\text { redução }\end{array}$ \\
\hline Atividades artísticas, criativas e de espetáculos & -77.176 & $88,3 \%$ \\
\hline Outras atividades administrativas e serviços complementares & -1.901 & $2,2 \%$ \\
\hline Comércio por atacado e varejo & -1.628 & $1,9 \%$ \\
\hline Atividades jurídicas, contábeis, consultoria e sedes de empresas & -916 & $1,0 \%$ \\
\hline Outras atividades profissionais, científicas e técnicas & -691 & $0,8 \%$ \\
\hline Transporte terrestre & -555 & $0,6 \%$ \\
\hline Atividades de vigilância, segurança e investigação & -375 & $0,4 \%$ \\
\hline Confecção de artefatos do vestuário e acessórios & -343 & $0,4 \%$ \\
\hline Manutenção, reparação e instalação de máquinas e equipamentos & -325 & $0,4 \%$ \\
\hline Impressão e reprodução de gravações & -271 & $0,3 \%$ \\
\hline
\end{tabular}

Fonte: Elaboração própria com base na matriz de insumo-produto do Brasil - 2015. 
Evidentemente, o setor cultural concentra a maior perda de postos de trabalho, com $88,3 \%$ do total. Em seguida, os setores de outras atividades administrativas e serviços complementares, e comércio por atacado e varejo, perdem, respectivamente, 1.901 e 1.628 vagas de emprego. Vale destacar que o setor de outras atividades administrativas e serviços complementares é o segundo maior fornecedor de insumos para o setor cultural, portanto, sendo bastante afetado pela redução na demanda deste último, seja em termos de mudança de produção, quanto em emprego.

O cálculo do multiplicador de empregos para o setor cultural aponta para um multiplicador de 1,16. Logo, para cada novo emprego no setor, haverá um total de 1,16 empregos criados na economia. Em outras palavras, se 100 empregos são criados no setor criativo, outras 16 vagas de trabalho são geradas nos demais setores da economia.

A redução na demanda final do setor cultural também exerce efeito sobre as remunerações dos trabalhadores do próprio setor, bem como - dados os efeitos multiplicadores - sobre a remuneração de toda a economia. Os dados indicam que o choque proposto reduz os rendimentos recebidos pelos trabalhadores do setor cultural em $\mathrm{R} \$ 859$ milhões. Ademais, o impacto sobre as remunerações dos demais setores é uma redução de $R$ \$ 302 milhões. A Tabela 5 exibe as informações para os 10 setores com maiores reduções de remunerações.

Tabela 5 Efeito gerador de rendimentos - Redução em 10\% na demanda final (2015)

\begin{tabular}{l|rr}
\hline Setores & $\begin{array}{r}\Delta \text { Produtos } \\
\text { R\$ milhões }\end{array}$ & $\begin{array}{r}\% \text { da } \\
\text { redução }\end{array}$ \\
\hline Atividades artísticas, criativas e de espetáculos & -859 & $74,02 \%$ \\
\hline Outras atividades administrativas e serviços complementares & -46 & $3,96 \%$ \\
\hline Comércio por atacado e varejo & -30 & $2,56 \%$ \\
\hline Intermediação financeira, seguros e previdência complementar & -29 & $2,48 \%$ \\
\hline Atividades jurídicas, contábeis, consultoria e sedes de empresas & -28 & $2,42 \%$ \\
\hline Outras atividades profissionais, científicas e técnicas & -15 & $1,33 \%$ \\
\hline Atividades de televisão, rádio, cinema e gravação/edição de som & -14 & $1,19 \%$ \\
\hline e imagem & -13 & $1,08 \%$ \\
\hline Administração pública, defesa e seguridade social & -12 & $1,06 \%$ \\
\hline Atividades de vigilância, segurança e investigação & -12 & $0,99 \%$ \\
\hline Transporte terrestre & &
\end{tabular}

Fonte: Elaboração própria com base na matriz de insumo-produto do Brasil - 2015. 
Os resultados para o multiplicador de renda apontam que, para cada real a menos no rendimento das famílias empregadas no setor cultural, há uma redução de $\mathrm{R} \$ 1,38$ no rendimento total da economia. Posto isso, fica evidente que o efeito de uma redução nos rendimentos auferidos pelos trabalhadores é propagado para os demais setores, visto que um menor rendimento em um setor, implica um menor consumo para essas famílias, exercendo impacto sobre toda a cadeia produtiva.

A cultura é capaz de gerar valor adicionado e produtividade para uma sociedade (Codes; Silva; Araújo, 2011; Cowen, 1996; DellaVigna; La Ferrara, 2015; Florida, 2002; Golgher, 2008; Machado; Simões; Diniz, 2013; Vivant, 2012). A despeito das heterogeneidades de consumo e de produção intrínsecas ao setor cultural, os resultados indicam que a atividade cultural é um importante impulsionador da economia no país, uma vez que os seus efeitos transbordam para outros setores. Assim, mesmo em uma economia onde a cultura é constituída basicamente segundo a lógica dos mercados, a dinâmica cultural parece fomentar o desenvolvimento econômico, em termos de produto, emprego e renda.

\section{Considerações finais}

A necessidade de se estudar economia da cultura relacionando a importância do setor como gerador de bem-estar social nas distintas realidades nacionais apresenta-se como um problema de pesquisa com muitas nuances ainda a serem exploradas. Tentando contribuir com esse debate, o presente artigo buscou analisar os impactos de uma hipotética redução no consumo de bens e serviços do setor cultural sobre a produção, rendimento e o emprego do próprio setor e sobre a economia em geral. Para tal, foi utilizado um modelo de insumo-produto, para o ano de 2015.

Os principais resultados revelam que a redução no consumo do setor cultural em $10 \%$ provoca perda de $\mathrm{R} \$ 2.7$ bilhões no produto do próprio setor, e uma perda adicional de $\mathrm{R} \$ 1.5$ bilhões em toda a economia, dada a interdependência setorial. De forma complementar, há redução de mais de 77 mil postos de trabalho no próprio setor que, quando considerado também os outros setores da economia, chega-se aproximadamente a 87 mil empregos a menos no país. Em síntese, além do efeito final sobre o produto ser maior, comparativamente ao choque inicial, há significativa 
redução no emprego e, por conseguinte, na renda da sociedade. Esses resultados, ainda que consideráveis, não captam todos os desdobramentos em termos de bem-estar e desenvolvimento econômico que podem ser atribuídos ao setor.

É importante destacar, por exemplo, a oportunidade que emerge da complementaridade entre entretenimento e educação, na combinação "entretenimento educativo". Os programas/serviços de entretenimento que incorporam lições de modelos a serem seguidos, em que o conteúdo colocado não é um produto, mas um comportamento social, apresentado de modo a ser imitado ou não, é um poderoso mecanismo de mudança social (DellaVigna; La Ferrara, 2015). Por todos esses aspectos, o debate sobre a economia da cultura é profundamente relevante.

A abertura do vetor de consumo e rendimento das famílias apresenta-se como um importante avanço futuro para este estudo. Assumir que o consumo das famílias esteja constituído por apenas uma única família representativa pode ser uma premissa simplificadora, uma vez que o consumo de bens culturais acontece de forma heterogênea entre diferentes grupos de renda. Assim, por meio da abertura do vetor de consumo e rendimento das famílias, é possível a identificação dos efeitos da mudança na demanda familiar, para grupos de renda específicos, sobre os setores da economia nacional.

Este estudo indica que a cultura é um setor que tem um impacto representativo sobre emprego e renda no Brasil. Atualmente questões como a política nacional de cultura e a proteção do patrimônio histórico e cultural estão nas mãos do Ministério do Turismo. O setor passa a ser um "anexo" do Ministério do Turismo, o que, juntamente com as constantes mudanças ocorridas, discutidas anteriormente, pode ser um indicativo do descaso que tem sido atribuído ao ramo cultural. O que os resultados sugerem é que a cultura deveria ser pensada como uma atividade estratégica para o desenvolvimento nacional. $O$ desmonte de um setor como o cultural pode ser desastroso para a sociedade. Nesse cenário, faz-se necessário pensar políticas de mercado para o setor cultural que, de fato, ajudem na emancipação do setor.

\section{Referências}

ALPER, Neil O.; WASSALL, Gregory H. Artists' Careers and Their Labor Markets. In: GINS- 
BURGH, VICTOR; THORSBY, DAVID (Org.). Handbook of the Economics of Art and Culture. Amsterdam: Elsevier, 2006. p. 813-864.

BAUMOL, William. Children of performing arts, the economic dilemma: The climbing costs of health care and education. Journal of Cultural Economics, v. 20, n. 3, p. 183-206, 1996.

BAUMOL, William; BOWEN, William. Performing arts: The economic dilemma. Massachussets: Yale University Press, 1966.

BENHAMOU, Françoise. Artists' labour markets. In: TOWSE, RUTH (Org.). A handbook of cultural economics. Cheltenham: Edward Elgar, 2003. p. 69-75.

BERG, Gunhild; ZIA, Bilal. Harnessing emotional connections to improve financial decisions: Evaluating the impact of financial education in mainstream media. Journal of the European Economic Association, v. 15, n. 5, p. 1.025-1.055, 2017.

BESHAROV, Gregory. The outbreak of the cost disease: Baumol and Bowen's founding of cultural economics. History of Political Economy, v. 37, n. 3, p. 413-430, 2005.

BOWITZ, Einar; IBENHOLT, Karin. Economic impacts of cultural heritage - Research and perspectives. Journal of Cultural Heritage, v. 10, n. 1, p. 1-8, 2009.

BRASIL. Lei n 13.808, de 15 de Janeiro de 2019.Planalto, Brasília, DF, jan de 2019. Disponível em: https://www2.camara.leg.br/orcamento-da-uniao/leis-orcamentarias/loa/2019. Acesso em: 10 de novembro de 2019.

BRYAN, J. et al. Assessing the role of the arts and cultural industries in a local economy. Environment and Planning A, v. 32, n. 8, p. 1391-1408, 2000.

BURSZTYN, Leonardo; CANTONI, Davide. A tear in the iron curtain: The impact of western television on consumption behavior. Review of Economics and Statistics, v. 98, n. 1, p. 25-41, 2016.

CHONG, Alberto; LA FERRARA, Eliana. Television and divorce: Evidence from Brazilian novelas. Journal of the European Economic Association, v. 7, n. 2-3, p. 458-468, 2009.

CODES, Ana Luiza Machado; SILVA, Frederico Augusto Barbosa; ARAÚJO, Herton Ellery. SIPS cultura: percepções e cultura. In: SCHIAVINATTO, FABIO (Org.). Sistema de Indicadores de Percepção Social (SIPS). Brasília: IPEA, 2011. p. 254.

COWEN, Tyler. Why I do not believe in the cost-disease. Journal of Cultural Economics, v. 20, n. 3, p. 207-214, 1996.

CUNHA, Alexandre M; BRITTO, Gustavo. When development meets culture: the contribution of Celso Furtado in the 1970s. Cambridge Journal of Economics, v. 42, n. 1, p. 177-198, 2017. Disponível em: <https://doi.org/10.1093/cje/bex021>. Acesso em: 10 nov. 2019

DELLAVIGNA, Stefano; LA FERRARA, Eliana. Economic and Social Impacts of the Media. In: ANDERSON, SIMON P; WALDFOGEL, JOEL; STRÖMBERG, DAVID (Org.). Handbook of Media Economics. Handbook of Media Economics. [S.1.]: North-Holland, 2015. v. 1. p. 723-768.

FLORIDA, Richard. The Rise of the Creative Class. New York: Basic Books, 2002.

FLORIDA, Richard. The rise of the creative class. Regional Science and Urban Economics, v. 35, n. 5, p. 593-596, 2005.

FURTADO, Celso. Formação cultural do Brasil. O longo amanhecer: reflexões sobre a formação 
do Brasil. Rio de Janeiro: Paz e Terra, 1999. p. 57-68.

GOLGHER, André Braz. As cidades e a classe criativa no Brasil: diferenças espaciais na distribuição de indivíduos qualificados nos municípios brasileiros. Revista Brasileira de Estudos de População, v. 25, n. 1, p. 109-129, 2008.

GOLGHER, André Braz. A distribuição de indivíduos qualificados nas regiões metropolitanas brasileiras: a influência do entretenimento e da diversidade populacional. Nova Economia, v. 21, n. 1, p. 109-134, abr. 2011.

GUILHOTO, Joaquim José Martins; SESSO FILHO, Umberto Antonio. Estimação da matriz insumo-produto utilizando dados preliminares das contas nacionais: aplicação e análise de indicadores econômicos para o Brasil em 2005. Revista Economia \& Tecnologia, v. 6, n. 23, p. 53-62, 2010.

IBGE. Matriz de insumo-produto: Brasil - 2015. Rio de Janeiro: IBGE, Coordenação de Contas Nacionais, 2018.

IBGE. Sistema de informações e indicadores culturais: 2007-2018. Rio de Janeiro: IBGE, Coordenação de População e Indicadores Sociais, 2019.

JÄGER, George Felipe Bond. Economia criativa e seus indicadores: uma proposta de indice para as cidades brasileiras. 2014. Dissertação (Mestrado em Engenharia de Produção) - Escola Politécnica, Universidade de São Paulo, São Paulo, 2014.

LA FERRARA, Eliana; CHONG, Alberto; DURYEA, Suzanne. Soap operas and fertility: Evidence from Brazil. American Economic Journal: Applied Economics, v. 4, n. 4, p. 1-31, 2012.

LAMEIRAS, Maria Andreia Parente et al. Carta de Conjuntura: Mercado de Trabalho. , no 43. [S.1: s.n.], 2019. Disponível em: <http://www.ipea.gov.br/portal/images/stories/PDFs/conjuntura/190618_cc_43_mercado_de_trabalho.pdf $>$. Acesso em: 10 nov. 2019.

MACHADO, Ana Flávia et al. Consumption of cultural goods and services and time allocation in Brazil. Nova Economia, v. 27, n. 1, p. 35-63, 2017.

MACHADO, Ana Flávia; PAGLIOTO, Bárbara Freitas; BRUZZI DE CARVALHO, Tereza. Creative Industries in Brazil: Analysis of Specifics Cases for a Country in Development. Theoretical Economics Letters, v. 08, n. 07, p. 1.348-1.367, 2018.

MACHADO, Ana Flávia; RABELO, Alexandre; MOREIRA, Arthur Gomes. Specificities of the artistic cultural labor market in Brazilian metropolitan regions between 2002 and 2010. Journal of Cultural Economics, v. 37, p. 1-15, 2013.

MACHADO, Ana Flávia; SIMÕES, Rodrigo Ferreira; DINIZ, Sibelle Cornélio. Urban Amenities and the Development of Creative Clusters: The Case of Brazil. Current Urban Studies, v. 1, n. 4, p. 92-101, 2013.

MARKUSEN, Ann; SCHROCK, Greg. The artistic dividend: Urban artistic specialisation and economic development implications. Urban Studies (Routledge), v. 43, n. 10, p. 1.661-1.686, 2006.

MILLER, Ronald E; BLAIR, Peter D. Input-Output Analysis: Foundations and Extensions. 2. ed. New York: Cambridge University Press, 2009.

SILVA, Frederico Barbosa. Economia e politica cultural: acesso, emprego e financiamento. Brasília: Ministério da Cultura, 2007. v. 3. 
SILVA, Frederico Barbosa; ARAÚJO, Herton Ellery; SOUZA, André Luis. O consumo cultural das famílias brasileiras. In: SILVEIRA, FERNANDO GAIGER et al. (Org.). Gasto e consumo das famílias brasileiras contemporâneas. 2. ed. Brasília: IPEA, 2007. p. 105-142.

TOHMO, Timo. Economic impacts of cultural events on local economies: An input-output analysis of the Kaustinen Folk Music Festival. Tourism Economics, v. 11, n. 3, p. 431-451, 2005.

VAUGHAN, Peter W. et al. Entertainment education and hiv/aids prevention: A field experiment in tanzania. Journal of Health Communication, v. 5, p. 81-100, 2000.

VIVANT, Elsa. O que é uma cidade criativa? São Paulo: Editora Senac São Paulo, 2012.

\section{Sobre os autores}

Marcus Vinícius Amaral e Silva - vinicius_amaral@msn.com Universidade Federal do Piauí, Teresina, Piauí, Brasil ORCID: https://orcid.org/0000-0002-9361-9448.

DanyellaJuliana Martins de Brito - danyjbrito@hotmail.com Universidade Federal de Pernambuco, Recife, Pernambuco, Brasil. ORCID: https://orcid.org/0000-0002-9630-2577.

\section{Sobre 0 artigo}

Recebido em 18 de novembro de 2019. Aprovado em 18 de fevereiro de 2020. 